\title{
J. T. Arlidge (1822-1899): a disillusioned alienist?
}

\author{
Edward Myers
}

\begin{abstract}
John Thomas Arlidge was a prominent allenist in the mid 19th century. After thitteen years involvement with asylum psychiatry in London he changed direction to become a physician in North Staffordshire, achieving fame as an expert in occupational disorders. This paper describes his contributions to the psychiatric ilterature and suggests that disaffection with the way psychiatry was progressing may have led to his change of career.
\end{abstract}

Those physicians who became well established in the new speciality of asylum psychiatry in the 19th century-men like Connolly, Bucknill, Browne, Maudsley and Clouston remained alienists (so-called because their patients were, by virtue of their illness, alienated from society) for the whole of their lives. An exception was John Thomas Arlidge who, after thirteen years of alienist practice in public asylums and licensed houses, during which time he contributed frequently to the literature on insanity and asylum psychiatry, completely forsook the speciality. He became, in 1862, Consultant Physician to the North Staffordshire Infirmary, devoting himself to the study of industrial medicine, in which subject he achieved fame in 1892 with a book on The Diseases of Occupation (Arlidge, 1892).

Arlidge was born at Chatham in the County of Kent on 17th July, 1822. The son of a doctor, he was educated at the Chatham and Rochester Classical and Mathematical School and, at the age of sixteen, was apprenticed to a general practitioner in the town of Rochester. He subsequently studied medicine at King's College, London, graduating M.B. and A.B. (Bachelor of Arts) in 1846, and winning prizes in anatomy, botany and divinity. In 1847 he was admitted to Membership of the Royal College of Physicians, becoming a Fellow in 1869, two years after obtaining his M.D.

After graduating in medicine, Arlidge worked under John Connolly and John Hitchman at Hanwell Asylum, Middlesex and was subsequently appointed resident medical officer and apothecary at St. Luke's Hospital for Lunatics in London. Here he abolished mechanical restraint and was responsible for the building of a chapel, recreation hall and ballroom as well as the provision of a laundry and sewing room for the female convalescent patients, and workshops for the men. On leaving St. Luke's in 1855 he travelled abroad, first with a patient in Europe, and then on his own in Egypt and Palestine. On his return to England he married Eliza Watts of Tottenham and was appointed Physician to the West London Hospital and to the Lunacy Dispensary, to the Belgrave and West Brompton and Chelsea Dispensary and to the Farrington Dispensary'. It would seem that, though he was still involved in treating the insane, he

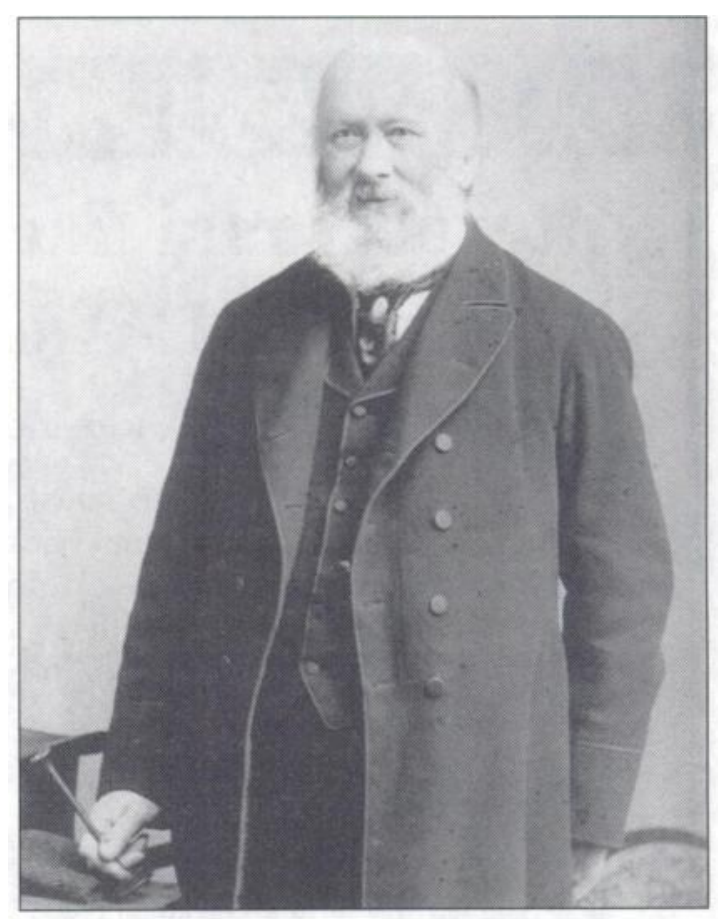

J. T. Arlidge (1822-1899) 
was beginning to develop interests outside psychiatry.

During his years as an alienist, Arlidge was a frequent contributor to The Asylum Journal and its successor. The Journal of Mental Science. In 'On the Examination of the Brain after Death', published in 1854 he makes the far-seeing comment that though the organic brain changes underlying insanity may be "inappreciable to our ordinary methods of research ... chemical investigation of the brain has been but little pursued and much may be expected from it". In 1855 he reviewed Pliny Earle's book on bloodletting in mental disorders: while agreeing with the author's conclusions to the effect that bloodletting was useless and often positively harmful he was crushing in his criticism of the method by which those conclusions had been reached.

In 1858 he wrote a highly critical article on the architecture of English asylums. Their design was important because "the asylum building is the machine through which the superintendent is to work out and develop his system of moral management". English asylums compared unfavourably with those on the Continent; the latter showed considerable variation in design whereas all English asylums were constructed on the same "monastery model" of corridors with a row of sleeping-rooms on one or both sides and one or two day-rooms, the whole constituting the twenty-four hour abode of the inmates. This arrangement, he contended, placed the patients "in circumstances, the very opposite of what obtains in the world at large". He put forward his own design for an asylum in which the day accommodation on the ground floor was completely separate from the night accommodation on the upper floor, except for that housing the old, infirm, paralytic and physically disabled who were to have small self-contained areas of their own. This arrangement would be "more like an ordinary home", it would give easier and healthier access to airing-courts and workshops during the day, it would be more economical in respect of warming, lighting and ventilation and it would require fewer attendants. The refractory, noisy and dirty patients were to have a separate detached wing. He estimated the cost of construction for a 220 patient asylum on the model he proposed to be $£ 19$ 000. Little notice was taken of Arlidge's suggestion and larger and larger monastictype edifices continued to make their appearance until well into the 20th century.
In 1862 Arlidge published a paper based on an analysis of the statistics provided by the reports of the official bodies responsible for overseeing the care of the insane in England, Scotland and Ireland. After allowing for difficulties in interpreting some of the figures, and discrepancies between the figures returned by the Lunacy Commissioners and the Poor Law Board in England, he is satisfied that pauper lunacy and chronic insanity are increasing and asks "are we proceeding in the right way with respect to our mode of provision for the insane?" He answers the question himself: "This state of things is most unsatisfactory and painful, considering the great endeavours made and the enormous expenditure undergone to provide for the treatment of the insane. and the impression will force itself on most minds that the plans adopted hitherto must be in some measure at least ineffectual, and that our method of providing for the insane must undergo a material change".

Arlidge put together his criticisms of the direction in which asylum psychiatry was moving, and his suggestions for improving matters, in his major work On the State of Lunacy and the Legal Provisions for the Insane with Observations on the Construction and Organization of Asylums (1859), a closely written book of 213 pages dedicated to the Earl of Shaftesbury, Chairman of the Lunacy Commission. Here again, he draws attention to the fact that, notwithstanding errors in the lunacy statistics, the proportion of mentally afflicted paupers in the population is increasing and that only half of those requiring supervision, control and treatment are as yet provided with asylum accommodation. Chronic lunacy is increasing partly because the stigmatising effect of asylum admission inhibits those who cannot afford private care from accepting treatment early enough. On the other hand, large numbers of pauper lunatics and imbeciles who have no alternative but to accept admission to an institution are being accommodated under deplorable conditions in workhouses where the law offers them no protection against false detention and makes no adequate provision to ascertain the treatment they are subjected to. He questions the validity of the economic argument for detaining pauper lunatics and imbeciles in workhouses rather than asylums and exposes the fallacy of 'dangerousness' as the sole criterion determining transfer from workhouse to asylum. The excessive size of asylums is condemned as is the inadequate medical staffing. Separate 
institutions for acute and chronic cases is advocated, those for the latter to be in the nature of 'cottage homes'. The Journal of Mental Science "heartily recommended" the book to its readers and commented that "although on some points the suggestions of its author for the improvement of the law are open to question, they will always be found worthy of attentive consideration, as emanating from an earnest, thoughtful, and highly instructed mind".

Arlidge's last contribution to the psychiatric literature was a detailed twenty-seven page analysis of Continental asylums, published in 1869 as an appendix to Sir James Clark's Memoir of John Connolly. By this time Arlidge had been physician to the North Staffordshire Infirmary for seven years and was no longer practically involved in the issues of asylum psychiatry. He could afford to be less critical and, on the whole found English asylums to compare favourably with their Continental counterparts. Buildings generally were "unsuited to their purpose" and all too large. Continental asylums were better staffed medically than in England and rated their medical staff more highly; some, however, still had no medical superintendent and the medical staff were under lay direction. Continental asylums lacked pictures on the walls, games and books; they evidenced a greater "display of strength and security in the general fittings and arrangements"; seclusion was more frequently employed and for longer periods and it was often not registered nor under the control of the medical officers. Mechanical restraint was least in Sweden, Denmark, France and Holland, but still much used in Italy and Germany. He concluded that most Continental alienists could benefit from visiting English asylums but few had so far availed themselves of the opportunity to do so.

Two questions arise. Why did Arlidge abandon a successful career in psychiatry and why, when he had more academically attractive opportunities - including the offer of the Chair of Medicine at Melbourne - did he choose to go to North Staffordshire as physician to the Infirmary? The answer to the first may be that he saw asylum psychiatry developing in a way with which he was unhappy and, rather than remain part of a system with which he was disaffected, he preferred to apply his considerable talents elsewhere. The answer to the second may be that he saw North Staffordshire with its high incidence of industrially caused illness in the potters and miners as an attractive area within which to pursue his burgeoning interest in occupational medicine. Whatever the reasons for Arlidge's change of direction, it is unlikely that, had he remained within the alienist fold, he would have had any significant effect upon the march of events, though the psychiatric literature would have been the richer for his continued contributions. As it was, psychiatry's loss was occupational medicine's (and North Staffordshire's) gain.

\section{Acknowledgements}

I am much obliged to Susan Floate, Librarian, Royal College of Psychiatrists for directing me to appropriate texts in the College Library, and to the North Staffordshire Medical Institute Archives for the photograph of Dr. Arlidge.

\section{References}

ARUDGE, J. T. (1854) On the examination of the brain after death. The Asylum Journal, 1, 29-30.

- (1855) An examination of the practice of blood-letting in mental disorders, by Pliny Earle. M.D. The Asylum Journal, 2. 167-175.

- (1858) On the construction of public lunatic asylums. Journal of Mental Science, 4, 188-204.

- (1859) On the State of Lunacy and the Legal Provision for the Insane with Observations on the Construction and Organization of Asylums. London: John Churchill.

- (1862) Lunacy statistics. Journal of Mental Science. 8. 417-429.

- (1869) Notes on Continental Asylums. In A Memoir of John Connolly. M.D.. D.C.L. Comprising a Sketch of the Treatment of the Insane in Europe and America (ed. Sir James Clark), pp. 228-255. London: John Murray.

- (1892) The Hygiene, Diseases and Mortality of Occupations. London: Perctval.

IsAaCson, E. (1974) The forgotten physician. In Historical Sketches of Medictine in the West Midlands (ed. West Midlands Physicians' Assoclation), pp. 34-40. Warwickshire: Warwickshire Publishing Company.

E. D. Myers, Honorary Research Fellow in Psychiatry, Department of Psychiatry. North Staffordshire Hospital, Keele University, Stokeon-Trent ST4 $7 Q B$ 